\title{
LIBERTAD DE EXPRESIÓN Y RELIGIÓN EN LA GULTURA LIBERAL DE LA MORALIDAD CRISTIANA AL MIEDO POSTSECULAR*
}

\section{FREEDOM OF EXPRESSION AND RELIGION IN THE LIBERAL GULTURE FROM THE GHRISTIAN MORALITY TO THE POST-SEGULAR FEAR}

\author{
Víctor J. VÁZQUEZ ALONSO**
}

RESUMEN: En el presente trabajo se aborda una cuestión recurrente en las modernas sociedades democráticas, que es la de hasta qué punto la tutela de los sentimientos religiosos puede servir como fundamento para establecer límites a la libertad de expresión dentro de una cultura liberal como es la del constitucionalismo. Para ello, en primer lugar, pondremos como ejemplo el paradigma jurídico de los Estados Unidos, donde desde la década de los años cincuenta la Corte Suprema ha afirmado la protección
ABSTRACT: This paper explores a common issue in the modern and pluralistic democratic societies: could the protection of religious feelings serves as a basis for establishing limits on freedom of expression? To do this, first, we will explore the constitutional paradigm of the United States, where since the early fifties the Supreme Court has affirmed the constitutional protection under the First Amendment to those discourses that may be offensive to certain religious communities. Subsequently, we will

* Artículo recibido el 31 de agosto de 2015 y aceptado para su publicación el 2 de febrero de 2016. Gran parte de las ideas de este trabajo han sido discutidas y en algunos casos literalmente apropiadas de Ignacio Garmendia, conocedor único de la historia de la censura artística y quien, precisamente por no ser jurista, me ha podido dar una noción más clara del significado último del delito de blasfemia en la historia. Igualmente, agradezco a los profesores Miguel Álvarez Ortega y María del Mar Leal Adorna las útiles sugerencias bibliográficas aportadas para la realización de este estudio.

Este artículo se terminó poco antes de los atentados cometidos contra los ilustradores de la revista francesa Charlie Hebdo. No he creído necesario modificar su contenido a raíz de este sucesos, ya que, más allá de que la cuestión de la blasfemia haya adquirido hoy una especial relevancia, las tesis aquí defendidas en nada han variado. En cualquier caso, se debe señalar que tales sucesos, más allá de suponer un atentado contra la libertad de expresión y contra la vida, pueden también considerarse la ejecución de una sentencia - de muerte- en su día avanzada, y, con ello, un desafío al propio monopolio del Estado en el uso legítimo de la fuerza, y, en definitiva, al corazón mismo de la idea de Estado de derecho..

** Doctor en derecho por la Universidad de Salamanca. Profesor del Departamento de Derecho Constitucional de Sevilla. 
constitucional bajo la primera enmienda de aquellos discursos que puedan resultar ofensivos para las comunidades religiosas. Posteriormente se analizará, a través del derecho comparado, cómo la tutela de la religión pervive en los ordenamientos jurídicos europeos, si bien ha sufrido una progresiva modificación en su fundamento. Posteriormente, se prestará atención a cómo en las sociedades postmodernas el nuevo blasfemo se sitúa dentro de la comunidad política al mismo tiempo que son las nuevas comunidades religiosas las que demandan protección de sus dogmas o símbolos. Finalmente, este trabajo intentará poner de manifiesto cómo la tutela de creencias o ideas religiosas frente a determinados discursos es incompatible con los presupuestos básicos de la cultura liberal. Para ello, se pondrá atención en la necesidad de diferenciar entre el discurso del odio dirigido contra las personas por razón su pertenencia a una religión y que puede ser objeto de límites, de aquel otro discurso que únicamente cuestiona, parodia o critica creencias o ideas religiosas, el cual no puede quedar al margen del amparo de la libertad de expresión.

Palabras clave: libertad de expresión - discurso del odio - libertad religiosa - pluralismo religioso. analyze through comparative law, how the religion's legal tutelage survives in the European legal systems, and how it has been gradually changed in its arguments with the secularization of the state. Subsequently, we will try to explain how in the postmodern societies the new blasphemous is now an insider of the political community while the new religious communities are the demanders of protection of their dogmas and symbols. Finally, this paper will attempt to show how the protection of beliefs or religious beliefs against certain offensive speech is incompatible with the basic assumptions of liberal culture. To this end, we will differentiate between hate speeches directed to certain individuals because of their religious affiliation, and other kind of discourse that only critics or affects religious beliefs or religious ideas which in any case could be excluded from the protection of freedom of expression.

Keyzeords: freedom of speech - hate speech religious freedom - religious pluralism. 
Esta revista forma parte del acervo de la Biblioteca Jurídica Virtual del Instituto de Investigaciones Jurídicas de la UNAM

SUMARIO: I. Introducción: blasfemar no es lo que era. II. Una lección previa de América: el pluralismo hace imposible (jurídicamente) lo sacrílego. III. Europa: las viejas Iglesias y el nuevo blasfemo. IV. La blasfemia y la difamación de la religión en el derecho internacional. La Europa de la ONU y la Europa del Tribunal Europeo de Derechos Humanos. V. La tipificación de la blasfemia y los presupuestos de la cultura liberal. VI. La blasfemia y el discurso del odio religioso. Una distinción necesaria.

\section{INTRODUCGIÓN: BLASFEMAR NO ES LO QUE ERA}

Entre 1740 y 1741 se representó en Francia una de las obras menores de Voltaire, la pieza teatral "El fanatismo o Mahoma. El profeta". La pieza resultó ser un éxito de público, pero finalmente su exhibición fue prohibida tras las presiones de la Iglesia católica. El interés eclesial para ello radicaba en que, bajo la sátira que en este texto se hacía de la figura del profeta, subyacía una crítica general al contenido dogmático de los monoteísmos y, en concreto, al propio catolicismo. La obra, en definitiva, trataba con irreverencia aquello que, en tanto fundamento prepolítico de la comunidad, no podría ser puesto en cuestión sin afectar a la propia esencia de la nación. Lo cierto es que, con posterioridad, la modernidad introducida por la Revolución francesa tampoco va a desterrar de Francia esta idea común a todos los países europeos, que es la de que el Estado ha de proteger la religión que da fundamento a la comunidad política. En realidad, no será sino hasta las Constituciones de la IV y la V República, cuando en Francia la laicidad se defina como principio constitucional la posición del Estado francés frente a todas las religiones. Sin embargo, sería ingenuo pensar que en el marco normativo de la actual Francia laica, el Mahoma de Voltaire se pudiera volver a representar con toda normalidad en los teatros franceses o en los de cualquier otro país europeo. Lejos de eso, la sátira de la figura histórica del profeta del islam sería vista por muchos como una intolerable provocación a la minoría islámica, y es más que probable que su exhibición supusiera una verdadera amenaza para el orden público.

En definitiva, queramos o no, la cuestión religiosa sigue suponiendo un particular desafio para el Estado constitucional, y, en este sentido, como sugiere Gauchet, tal vez no haya cambiado tanto la idea del secularismo como sus contrarios. Así, si la discusión principal fue durante años el alcance jurídico del proceso de desconfesionalización que impone la 
Esta revista forma parte del acervo de la Biblioteca Jurídica Virtual del Instituto de Investigaciones Jurídicas de la UNAM

lógica de la laicidad, en la actualidad, a este debate se superpone hoy otro distinto, que gira sobre la concreta cuestión de qué forma ha de adoptar la neutralidad para integrar un pluralismo religioso con características inéditas. El famoso y arriesgado vaticinio de André Malraux, de que el siglo XXI sería necesariamente religioso, no pudo ser a la postre más acertado, y es fácil observar cómo hoy las democracias liberales se enfrentan con cierta improvisación y sorpresa al hecho de que antes de hacerse cierta la idea de una sociedad postcristiana ${ }^{1}$ se han hecho visibles las demandas de una nueva sociedad postsecular, ${ }^{2}$ en la que las identidades religiosas vuelven a hacerse presentes en el discurso público, poniendo en cuestión ciertos presupuestos de la neutralidad liberal.

En cualquier caso, dentro de este proceso simultáneo de desconfesionalización e integración al que se ha aludido, la religión sigue siendo en muchos ámbitos una cuestión constitucionalmente diferente. A este respecto, y ya centrándonos en el tema que nos ocupa, que es el del discurso del odio religioso, lo cierto es que, con respecto a los límites que puedan imponerse a la libertad de expresión en este ámbito, se plantea un problema específico, y éste es el de si los sentimientos y las creencias religiosas de las personas requieren de una tutela jurídica particular frente a los ataques que se hagan a los dogmas de su fe. Es decir, que si bien dentro del debate general sobre el hatespeech, el discurso que incite a la violencia o que denigre a las personas que practican una determinada religión puede abordarse desde los mismos parámetros que aquel otro que fije sus objetivos en la raza, en la orientación sexual o en la nacionalidad; en el ámbito religioso se plantea una cuestión singular, y ésta es la de qué respuesta jurídica ha de darse en aquellos supuestos en los que el discurso no constituye un ataque a la reputación o al estatus social de los creyentes, sino un ataque contra sus creencias o contra los dogmas y símbolos de su fe.

La razón de esta particularidad podríamos decir que reside, en principio, en el simple hecho de que las creencias ocupan en el hombre un lugar diferente al de las ideas. Las ideas se tienen, en las creencias se está, son el lugar en el cual el hombre se sitúa ante el mundo, dando así respuesta al propio sentido de su existencia. ${ }^{3}$ En este sentido, cuando el hombre se da

1 Vattimo, Gianni, Después de la cristiandad. Por un cristianismo no religioso, Barcelona, 2002.

2 Willaime, Jean-Paul, "Religion in Ultramodernity", Teorising Religion: Classical and Contemporany Debates, Ashgate, 2006, pp. 73-85.

3 Ortega y Gasset, José, Ideas y creencias, p. 29. 
Esta revista forma parte del acervo de la Biblioteca Jurídica Virtual del Instituto de Investigaciones Jurídicas de la UNAM

una respuesta positiva al fenómeno religioso abrazando un determinado culto, surge una relación singular de identidad con el conjunto de dogmas y símbolos de su fe, hasta el punto de que las críticas hacia éstos suponen también una ofensa hacia su propia persona. El hombre religioso, en definitiva, sitúa sus creencias en un lugar de específica sensibilidad. Alguno objetará, con razón, que quien se da una respuesta negativa al fenómeno religioso también cree - cree que no cree-, pero también tendrá que aceptar el que, por ejemplo, no tiene el mismo impacto sobre los sentimientos de un marxista la mofa o la revisión histórica que alguien pueda hacer de la vida de Marx que la que tiene para un cristiano la que se haga de Jesucristo. Nos movemos aquí en dos ámbitos diferentes del ser. ${ }^{4}$

Pero, más allá de esto, no debe olvidarse que si bien hoy el dilema de hasta qué punto el derecho ha de estar al servicio de la protección de las religiones frente a determinados discursos tiende a plantearse desde la perspectiva de la protección de los sentimientos religiosos, en origen, no es sino una vieja cuestión vinculada a las relaciones entre el Estado y las religiones. La idea de proteger los dogmas o símbolos de una determinada religión frente a la libertad de expresión es tan antigua, en este sentido, como lo es la tipificación penal de la blasfemia, una figura delictiva cuya lógica por otro lado ha estado íntimamente vinculada a la del confesionalismo. Como expuso muy bien la "Comisión de Ofensas Religiosas" de la Cámara de los Lores británica, tras la prohibición penal de la blasfemia lo que originalmente subyace es esa idea de que "la fe ha de ser vista como la raíz de la sociedad política y del comportamiento moral". Y que, por lo tanto "los desafíos a esa fe o sus ofensas deben de considerarse serias amenazas contra la esencia de la sociedad política y moral de la nación y hay que castigarlos severamente". ${ }^{5}$

A este respecto, no es muy difícil tampoco vincular la tipificación del delito de blasfemia con el propio concepto de "derecho de la moralidad" que esbozara lord Devlin ${ }^{6}$ en su disputa con Hart, ${ }^{7}$ a propósito de la cons-

4 Eliade, Mircea, Lo sagrado y lo profano, Barcelona, 1999; Durkheim, Émilie, Las formas elementales de la vida religiosa, en especial, pp. 29-42.

5 House of Lords Select Committee on Religious Offences in England and Wales, First Report (2002-2003) vol. I, appendix 3, párr. 2.

6 Devlin, Lord, The Enforcement of Morals, Oxford, 1959.

7 Hart, H. L. A., Law, Liberty and Morality, Oxford, 1963. Igualmente, una crítica clásica a la obra de Devlin, también desde presupuestos liberales, la podemos encontrar en 
Esta revista forma parte del acervo de la Biblioteca Jurídica Virtual del Instituto de Investigaciones Jurídicas de la UNAM

titución de la Comisión Wolfenden sobre la destipificación del delito de homosexualidad o prostitución en Inglaterra. ${ }^{8}$ En este sentido, la lucha contra lo blasfemo no se diferencia demasiado en su fundamento de la lucha contra lo obsceno o lo indecente, ${ }^{9}$ y es que, con la tipificación penal de la blasfemia, en definitiva, el derecho se pone al servicio de la integridad moral de la sociedad, sancionando aquellos discursos que provocan un profundo y verdadero sentimiento de repugnancia, y que por ello amenazan con desestructurar moralmente la comunidad. ${ }^{10}$ Ahora bien, esta idea de moralidad religiosa presupone, en gran medida, o bien una sociedad no pluralista o bien un Estado que no ha renunciado a afirmar su identidad política sobre una preexistente identidad religiosa. En este sentido, como veremos, a medida que se consolida el pluralismo religioso y se avanza en el proceso de desconfesionalización de los Estados, el delito de blasfemia emerge como un tipo penal cuya lógica es difícil de conciliar con los presupuestos igualitarios y liberales del constitucionalismo y que, por lo tanto, requiere o bien su derogación, o bien su replanteamiento a la luz de estos principios.

No obstante, aunque los viejos blasfemos, es decir, aquellos outsider que atacaban la religión del Estado y la propia estructura moral mayoritaria en una sociedad, ya no constituyan un problema central para el Estado constitucional, esto no ha significado la muerte real del debate jurídico sobre la blasfemia. Como decíamos, dentro del nuevo paradigma de relaciones entre el Estado y la religión, los viejos problemas jurídicos de derecho de las religiones, más que desaparecer, se reformulan a la luz de un nuevo

Dworkin, Ronald, "Lord Devlin and the Enforcement of Morals", 75 Tale Law fournal 987, 1965-1966.

8 The Wolfenden Rapport. Committee on Homosexual Offenses and Prostitution, núm. 247, 1957.

9 El episodio que voy a citar es sin duda soez, pero no deja de ser ilustrativo. Cuentan sus biógrafos que Álvaro de Retama, poeta maldito de la España de principios del pasado siglo, se salvó de la pena de muerte en un juicio por sacrilegio, justo después de la guerra civil, de la siguiente forma. Acusado por el tribunal de beber semen en vasos consagrados, el poeta de Retama contestó que él siempre había bebido el semen directamente, una confesión que le valió la cárcel por obsceno, pero que le libraba de la condena por blasfemia. Véase Villena, Luis Antonio de, El ángel de la frivolidad y su máscara oscura. Vida, literatura y tiempo de Álvaro de Retama, Madrid, 1991, p. 94. Sobre cómo la idea del "enemigo moral" de la sociedad fue acogida, en clave confesional, por la legislación penal española, véase, en extenso, Martín, Sebastián, "Criminalidad política y peligrosidad social en la España contemporánea”, Quaderni Fiorentini, núm. 38, 2009, en especial, pp. 864-865 y 936-937.

10 Devlin, Lord, The Enforcement..., cit., pp. 8-25. 
Esta revista forma parte del acervo de la Biblioteca Jurídica Virtual del Instituto de Investigaciones Jurídicas de la UNAM

pluralismo, donde los grupos sociales conviven con un equipaje religioso muy dispar. El conflicto entre libertad de expresión y religión se presenta así entre un nuevo blasfemo que se sitúa en el centro de la conciencia secular y crítica de la sociedad y determinadas minorías religiosas, para las cuales constituye algo inédito la irreverencia contra los dogmas de su fe. En cualquier caso, como veremos, al igual que en tantos otros ámbitos, el punto de partida sobre el que se afronta este desafío es muy diferente en la tradición constitucional norteamericana y la europea: desde una realidad jurídica plenamente secular, en el primer caso, y en un proceso aún imperfecto de secularización en el segundo.

\section{UNA LEGGIÓN PREVIA DE AMÉRICA: EL PLURALISMO HACE IMPOSIBLE (JURÍDICAMENTE) LO SACRÍLEGO}

Son muchos los trabajos históricos que a estas alturas han puesto ya de manifiesto la excesiva mitificación de la tolerancia religiosa en la América temprana. Concretamente, en la era colonial la tipificación de la blasfemia no fue algo excepcional, como no lo fue tampoco la persecución de los disidentes religiosos en muchas colonias donde existía un determinado sustrato protestante hegemónico. Como ha explicado muy bien el profesor McConnell, incluso después de aprobada la primera enmienda de la Constitución de los Estados Unidos, diversos estados mantuvieron de facto la oficialidad de determinados cultos, y en algunos de ellos la tipificación penal de la blasfemia siguió vigente hasta bien entrado el siglo XX, cuando se inicia una progresiva destipificación o desuso de estas normas. ${ }^{11}$ Sin embargo, esto no quiere decir que el respeto a lo sagrado no siguiera constituyendo un límite a la libertad de expresión. Así, al margen del derecho penal, las expresiones de tipo blasfemo o sacrílego siguieron siendo susceptibles de ser censuradas a nivel estatal hasta que un tribunal supremo ya decididamente liberal, como era el de los primeros años cincuenta, decidió extender la protección de la primera enmienda a este tipo de expresiones en la conocida sentencia foseph Burstyn, Inc. v. Wilson. ${ }^{12} \mathrm{El}$ contenido de este litigio no deja de ser emblemático. Se trataba de valorar la adecuación a la primera enmienda de la prohibición que había decretado el Estado de

11 McConnell, Michael, "The Origins and the Historical Understanding of Free Exercise of Religion", 103 Harvard Law Review, mayo de 1990, pp. 1409 y ss.

12 Joseph Burstyn, Inc. v. Wilson, 343 U.S. 495 (1952). 
Esta revista forma parte del acervo de la Biblioteca Jurídica Virtual del Instituto de Investigaciones Jurídicas de la UNAM

Nueva York contra la exhibición y distribución de la película del director italiano Roberto Rossellini El milagro. Para ello, el Estado de Nueva York se había apoyado en una normativa educativa que vetaba la exhibición de contenido sacrílego. En concreto, lo sacrílego de la película El milagro era el relato que ésta hacía de cómo San José dejaba embarazada a una campesina demente, haciéndola luego creer que era la virgen María. Pues bien, para la Corte Suprema, la primera enmienda de la Constitución no permite a los poderes públicos, establecer restricciones previas a la libertad de expresión con el objetivo de proteger la religión o determinadas comprensiones religiosas de aquellas visiones de las mismas que puedan resultar incómodas.

La sentencia del Tribunal en foseph Burstyn, Inc. v. Wilson avanzaba así una nueva comprensión, luego consolidada, del arte como manifestación de la libertad de expresión, ${ }^{13}$ al tiempo que rechazaba que el Estado pudiera esgrimir como interés legítimo para su limitación la salvaguarda del dogma religioso. ${ }^{14}$ A pesar de la importancia de la opinión de la Corte, creo que las páginas más esclarecedoras de este litigio, en relación con la cuestión que nos ocupa, se encuentran en el voto particular concurrente del juez Frankfurter, quien acude a la propia idea de pluralismo para fundamentar la imposibilidad constitucional de proteger lo sagrado en un contexto como el estadounidense. Para el juez, el estado de Nueva York había dado sentido jurídico al concepto de "sacrilegio" a través, exclusivamente, de los textos de Agustín de Hipona y del padre Tomás de Aquino. Sin embargo, después de bucear por distintos diccionarios de la lengua inglesa para intentar dotar de un significado secular a este concepto, Frankfurter demuestra la imposibilidad de encontrar una idea común de lo "sacrílego" en los Estados Unidos. ${ }^{15}$ Algo que sí sería

13 Con esta sentencia, la Corte Suprema deroga el precedente establecido en Mutual Film Corp. v. Industrial Commission, 236 U.S. 230 (1915), una decisión en la cual la mayoría del Tribunal había interpretado que el cine era propiamente un producto industrial que, en ningún caso, podía verse amparado por la primera enmienda como una de aquellas manifestaciones de la libertad de expresión que de alguna forma contribuyen a la formación de opinión pública.

14 Sobre las muchas implicaciones, también económicas, de este cambio jurisprudencial, puede verse, en extenso, Wertheimer, John, "Mutual Film Reviewed: The Movies, Censorship, and Free Speech in Progressive America", 37 The American Fournal of Legal History, April 1993, pp. 158-189.

15 (Frankfurter Concurring) Foseph Burstyn, Inc. v. Wilson 343 U.S. 507-540, (1952) “...in America, the multiplicity of the ideas of «sacredness» held with equal but conflicting fervor 
Esta revista forma parte del acervo de la Biblioteca Jurídica Virtual del Instituto de Investigaciones Jurídicas de la UNAM

posible en países donde existe una religión de Estado, como Inglaterra, pero no en un territorio donde no sólo no hay un Iglesia establecida, sino en el cual el pluralismo religioso es tan exacerbado que, parafraseando al juez Roberts en Cantwell v. Conneticut, resulta habitual que las creencias y las propias conductas religiosas de uno puedan resultar sacrílegas para su vecino. ${ }^{16}$ La asunción progresiva de la doctrina de la Corte Suprema sobre la primera enmienda por parte de los jueces estatales ${ }^{17}$ ha hecho que, bajo estos parámetros, el discurso ofensivo contra el contenido dogmático de las religiones esté plenamente amparado por la libertad expresión; todo ello, paradójicamente, en una sociedad como la estadounidense, de la que bien puede decirse que es la más religiosa de Occidente. ${ }^{18}$

\section{EUROPA: LAS VIEJAS IGLESIAS Y EL NUEVO BLASFEMO}

En el contexto europeo las cosas han sido diferentes, y es que, en realidad, el reconocimiento pacífico del pluralismo religioso dentro de los Estados es algo relativamente tardío, sin que haya habido nación que, no ya en el siglo XIX, sino durante el propio siglo XX, no haya sucumbido a la tentativa de salvaguardar un cierto grado de unidad religiosa o de trasladar el sustrato moral de la confesión mayoritaria al ordenamiento jurídico. La resistencia penal del delito de blasfemia o de los delitos de escarnio o vilipendio de la religión estatal ha sido, en este sentido, muy superior en el continente europeo que en la otra tradición atlántica del constitucionalismo. Así, no ha sido sino hasta bien entrado el último cuarto del siglo

by the great number of religious groups makes the term «sacrilegious» too indefinite to satisfy constitutional demands based on reason and fairness".

16 Cantwell v. Connecticut, 310 U.S. 296 (1940), donde la mayoría del tribunal entiende que la condena a un testigo de Jehová por haber atacado en un acto de proselitismo a la Iglesia católica era contraria a la cláusula de libre ejercicio de la religión de la primera enmienda. En la nación americana, señala Roberts, redactando la opinión de la mayoría, "in the realm of religious faith, and in that of political belief, sharp differences arise. In both fields, the tenets of one man may seem the rankest error to his neighbor. Conduct and beliefs dear to one may seem the rankest «sacrilege» to another".

17 Brennan, William J., "State Constitutions and the Protection of Individual Rights", 90 Harvard Law Review, 1977, pp. 489-504.

18 Bloom, Harold, La religión de los Estados Unidos. El surgimiento de la nación postcristiana, México, 1997. 
Esta revista forma parte del acervo de la Biblioteca Jurídica Virtual del Instituto de Investigaciones Jurídicas de la UNAM

XX cuando, ante la imposibilidad de conciliar la tutela privilegiada de ciertas religiones con las exigencias derivadas del principio de igualdad y de una comprensión democrática de la libertad de expresión, la tutela penal de las religiones ha experimentado un proceso de transformación no siempre similar en todos los países europeos. Y es que, como demuestran los estudios de derecho comparado, la intensidad en la tutela penal de la religión, a través de los delitos de blasfemia o de difamación de la religión, ha resistido más o menos, en función de la propia resistencia de la confesionalidad del Estado o la estatalidad de una determinada Iglesia. De esta forma, como iremos viendo en adelante, en algunas experiencias el delito de blasfemia sobrevive como un residuo de la confesionalidad estatal, mientras que en otras, el letargo del tipo penal ha conducido a su derogación o a una reformulación del injusto en la cual el bien jurídico protegido no es ya la moralidad o la identidad religiosa del Estado, sino los sentimientos religiosos de los ciudadanos o, en último término, el orden público.

En cualquier caso, al contrario de la norteamericana, la experiencia europea con respecto a la tutela penal de las religiones es, en muchos casos, una experiencia que podríamos calificar de indecisa o vacilante. Y es que, en la misma medida en que se ha ido abandonando la idea de que los instrumentos punitivos del Estado no han de estar al servicio de la identidad o de la moralidad religiosa del país, ha surgido un nuevo ámbito de indecisión en torno a la necesidad de mantener tipos penales análogos, orientados en este caso a la protección de ciertas minorías religiosas, y también de la propia paz social. En este proceso es especialmente visible en todo momento una influencia emancipadora proveniente de la libertad artística, y es que el arte ha servido en muchos casos como un contrapunto de irreverencia frente a las tentativas de limitar aquellos discursos que puedan resultar ofensivos contra la religión. En cualquier caso, el espacio europeo, pese a enfrentarse a problemas cada vez más comunes con relación a la gestión del pluralismo religioso, es un espacio diacrónico en lo referente a los procesos de secularización, de tal forma que el marco jurídico vigente para afrontar estos nuevos desafíos propios de sociedades plurales en lo religioso presenta, como veremos, importantes diferencias entre los distintos países. 
Esta revista forma parte del acervo de la Biblioteca Jurídica Virtual del Instituto de Investigaciones Jurídicas de la UNAM

\section{La desconfesionalización de la blasfemia: Inglaterra, España, Italia}

Un buen ejemplo de esa relación de tensión entre la libertad artística y la tutela de lo sagrado ha sido la experiencia dentro de un modelo de Iglesia de Estado como es el de Inglaterra, uno de los países, donde, por otro lado, más tiempo ha permanecido inalterado este tipo penal de la blasfemia, que prohibía todo ultraje o ridiculización relacionada con Dios, Jesucristo o la Biblia, o los fundamentos de la Iglesia anglicana. Lo cierto es que durante gran parte del siglo XX el delito de blasfemia había vivido en una suerte de letargo judicial. ${ }^{19}$ En realidad, que tenga conocimiento, el único proceso penal exitoso por este delito que se produce en muchos años es el que se llevó a cabo en 1979 contra la revista Gay Newes por la publicación del poema de Jemes Kirkup The Love That Dares to Speak its Name. Una composición en la cual se recrean escenas de sexo entre Jesús, sus discípulos y otros protagonistas de pasajes evangélicos, como los centuriones romanos que custodiaron a Jesús de Nazaret o el propio Poncio Pilato. La condena a la revista Gay News, lejos de rehabilitar los límites contra determinados discursos ofensivos de la religión, en realidad lo que inició fue un proceso de reflexión sobre la necesidad de derogar este delito de expresión en el ordenamiento británico. Años más tarde, con la publicación de la conocida novela Los versos satánicos de Salman Rushdie, esta tendencia se agravó, y es que el proceso judicial abierto contra el escritor por la publicación de esta obra puso de manifiesto la lógica profundamente discriminatoria sobre la que se afirmaba la legislación contra la blasfemia en Inglaterra, ya que ésta sólo protegía a la religión anglicana, con lo cual en ningún caso resultaba subsumible dentro del tipo penal la obra de Rushdie que, como es conocido, resultaba ofensiva para la religión musulmana por su contenido. En 2003, el Comité de Ofensas Religiosas de la Cámara de los Lores llamó la atención sobre lo inaceptable de esta discriminación en el ámbito del Consejo de Europa y sobre la propia falta de proporcionalidad de las restricciones que este tipo penal impone sobre la libertad de expresión. ${ }^{20}$ En este contexto, en 2008 el delito de blasfemia va a ser finalmente derogado, si bien es necesario subrayar que la tutela

19 Hill, Mark y Sand Berg, Russell, "Blasphemy and Human Rights: An English Experience in a European Context", Law and Religion, núm. 4, pp. 145-159.

20 Cuestionando esta teórica falta de adecuación de la legislación inglesa a la luz de la jurisprudencia del Tribunal Europeo de Derechos Humanos en los asuntos Otto Preminger $c$. 
Esta revista forma parte del acervo de la Biblioteca Jurídica Virtual del Instituto de Investigaciones Jurídicas de la UNAM

frente al discurso del odio religioso ya había situado el bien jurídico protegido en un ámbito diferente, con la aprobación del Racial and Religious Hatred Act en 2006, ${ }^{21}$ una nueva legislación en la que se tipifica específicamente la incitación al odio religioso. En Inglaterra, en este sentido, se produce una diferenciación entre los ataques a la religión, que desde 2008 no son perseguibles penalmente, y los ataques contra determinados grupos de personas, caracterizados por la tenencia común de un credo, que sí serían, en este caso, susceptibles de sanción penal. ${ }^{22}$

En el ordenamiento español puede decirse igualmente que la afirmación de la laicidad del Estado ha significado a la postre la destipificación penal de la blasfemia. Desde el punto de vista histórico, en el derecho penal español había existido una suerte de dinámica pendular en lo que se refiere a los "delitos contra la religión”, oscilando así entre la protección penal exclusiva del corpus doctrinal de la religión católica, y la apertura en los códigos liberales hacia la garantía frente al escarnio de todas aquellas religiones con prosélitos en España. ${ }^{23}$ En cualquier caso, en el contexto de una Constitución como la vigente en España, que garantiza la libertad de expresión y excluye el carácter estatal de cualquier confesión, la tutela penal del contenido dogmático de las confesiones tiene un difícil encaje. Parece claro, en este sentido, que el principio de laicidad del Estado excluye que el legislador pueda hacer una valoración de lo religioso en sí mismo considerado, sustrayendo el corpus doctrinal de las confesiones del ámbito de lo cuestionable. Es por esto que el Código Penal de 1995 se apartó de esta tradición histórica al destipificarlo el delito de blasfemia. Sin embargo, esto no significó la eliminación de todo tipo de sanción penal frente a los discursos que puedan resultar ofensivos para las religiones. Con la aprobación del Código Penal de 1995 el legislador quiso

Austria y Wingrove c. Reino Unido, véase Hill, Mark y SandBerg, Russell, "Blasfemy and Human Rights Context...", cit., pp. 152-157.

21 Existe, en este sentido, una cierta relación de causalidad entre una y otra decisión, como explican Sandberg, Rusell y Doe, N., en "The Strange Death of Blasphemy", 71 Modern Law Review 97 1, 2008.

22 Jeremy, Anthony, "Practical Implications of the Enactment of the Racial and Religious Hatred Act 2006”, 9 Ecclesiastical Law Fournal, pp. 187-201.

23 Para un estudio detallado de la evolución histórica de la tutela penal de la religión en España, véase Ferreiro Galguera, Juan, Protección jurídico penal de la religión, Coruña, 1998, en especial, pp. 86-187. 
Esta revista forma parte del acervo de la Biblioteca Jurídica Virtual del Instituto de Investigaciones Jurídicas de la UNAM

ofrecer una tutela específica a los sentimientos religiosos, ${ }^{24}$ tipificando como delito en el artículo 525 la conducta de quien, con el objetivo de ofender estos sentimientos, "haga públicamente, de palabra, por escrito o mediante cualquier tipo de documento, escarnio de sus dogmas, creencias, ritos o ceremonias, o veje, también públicamente, a quienes los profesan o practican". ${ }^{25}$

Como señalábamos, no puede decirse que con el artículo 525 del Código Penal español el delito de blasfemia siga estando tipificado en nuestro ordenamiento. En este caso, como se puede apreciar, el bien jurídico tutelado no es el corpus doctrinal de una confesión o de todas las confesiones, sino los sentimientos religiosos de los ciudadanos. No obstante, de los términos en los que esta tutela ha sido establecida, sí puede afirmarse que, en gran medida, el artículo 525 constituye un sucesor del viejo tipo penal de escarnio de la religión adaptado a las exigencias constitucionales. A este respecto, el problema es que, en esa adaptación, el tipo penal se desfigura del tal forma que, como ha señalado la doctrina penalista, parece difícil imaginar su viabilidad práctica. ${ }^{26}$ Se trata, en definitiva, de un tipo penal cargado de subjetivismo — se protegen los sentimientos-, en el que es complicado determinar la existencia real de un daño, y que, a su vez, exige un ánimo específico muy difícil de constatar en la práctica. ${ }^{27}$ Sin

24 Véase, en extenso, Ferreiro Galguera, Juan, "Libertad religiosa e ideológica: garantías procesales y tutela penal", Anuario da Facultade de Dereito, en especial, pp. 382 y ss.

25 Del mismo modo, en el número dos de este artículo, y con la intención de disipar cualquier duda acerca del sesgo confesional de este delito, se extiende, de una forma, en mi opinión, algo pueril, la tutela penal frente al escarnio público de sus creencias a quienes no profesan religión o creencia alguna.

26 Gugat, Miriam, "Acerca de la protección penal e los sentimientos religiosos en los medios de comunicación. Pluralismo religioso y medios de comunicación", Medios de Comunicación y Pluralismo, Consell de l'Audiovisual de Cataluyna, marzo de 2010, pp. 42-45.

27 Vives Antón, Tomás y Carbonel, Mateu, "Delitos contra la libertad de conciencia, los sentimientos religiosos y el respeto a los difuntos", Derecho penal, Parte especial, Valencia, 2010. En sentido contrario, pueden verse los trabajos de la profesora Pérez Madrid, para quien "el sentimiento religioso... es algo merecedor de tutela penal como expresión de la personalidad, como momento central de una dignidad, por decir así, existencial, como dato originario e inherente de la naturaleza humana". Véase Pérez-Madrid, Francisca, "Incitación al odio religioso o ¿hate speech? y libertad de expresión", Revista General de Derecho Canónico y Eclesiástico del Estado, núm. 19, 2009, pp. 23 y 24; y, en extenso, su monografía, La tutela penal de la libertad religiosa en el derecho español, Universidad de Navarra, 1995, en especial, pp. 228 y ss. 
Esta revista forma parte del acervo de la Biblioteca Jurídica Virtual del Instituto de Investigaciones Jurídicas de la UNAM

olvidar, por otro lado, que en todos los supuestos donde sea apreciable el ejercicio legítimo de la libertad de expresión no será posible concluir la tipicidad de la conducta. ${ }^{28}$ Todas estas dificultades se han puesto de manifiesto en un litigio reciente que adquirió una cierta relevancia mediática. Se trata del juicio contra Javier Krahe por la emisión en 2004 de un cortometraje ideado por él en 1977, como promoción de un trabajo discográfico, y en el cual, bajo el título Cristofagia, se recreaban los pasos de una receta para cocinar un Cristo crucificado. La sentencia del juzgado de lo Penal de Madrid que conoció de la demanda subrayó, en este sentido, tanto la imposibilidad de constatar el ánimo específico de menoscabar o humillar los sentimientos de terceros que exige el tipo penal como la propia necesidad de atender en este tipo de supuestos al "sentido satírico, provocador y crítico", que es usual en ciertas expresiones artísticas, y que excluiría, igualmente, cualquier connotación ofensiva que pudiera dar lugar a responsabilidad penal. ${ }^{29}$

Una evolución parecida la podemos observar en el caso de un país católico como Italia, en el cual la depuración de ciertos residuos de confesionalidad presentes en su ordenamiento ha resultado una tarea costosa y, en algunos casos, inacaba. Así, el Código Penal italiano punía respectivamente el delito de vilipendio de la religión y el delito de blasfemia únicamente cuando ambas acciones afectaran a la religión católica, en

28 En realidad, las demandas penales con base en el artículo 525 del Código Penal han sido testimoniales y, por lo menos en lo que tengo conocimiento, en todas ellas la ausencia del ánimo específico ha conducido a la absolución del demandado. Así, el Tribunal Supremo - STS 669/93 del 25 de marzo - entendió que no existía ánimo de ofender en quienes en un vídeo musical utilizaban la imagen de un crucificado con la cabeza de un carnero en vez de la de Jesucristo. Igualmente, la Sala Penal de la Audiencia Provincial de Sevilla — ST núm. 553/04 del 7 de junio - absolvió al autor de una imagen en la cual la virgen María aparecía con los genitales de un varón, al considerar que no era probada la intención de herir los sentimientos religiosos de los católicos por parte de su autor. En Valladolid, la Audiencia Provincial -ST Secc. 2a., núm. 251/11, del 9 de junio de 2011 - confirmó la absolución de quien se había paseado durante la Pascua de Resurrección con una imagen de la Piedad subtitulada con la frase "la adúltera y el bastardo", basándose, en este caso, en la evidente falta de salud mental del demandado. Sobre esta jurisprudencia, y en general, sobre la protección penal de la libertad religiosa en España, véase, en extenso, Minteguía Arregui, Igor, Sentimientos religiosos, moral pública y libertad artística en la Constitución española de 1978, Madrid, 2006, en especial, pp. 210-305.

29 Sentencia 235/12 del Juzgado de lo Penal de Madrid, núm. 8, del 12 de junio de 2012, en especial fjo. 3 y 4. 
Esta revista forma parte del acervo de la Biblioteca Jurídica Virtual del Instituto de Investigaciones Jurídicas de la UNAM

tanto religión del Estado italiano. La Corte Constitucional, después de una primera jurisprudencia, en la que justificó este privilegio con base en lo que algún autor definió como "criterios histórico cuantitativos", ${ }^{30}$ va a desempeñar a partir de 1995 y en sucesivas sentencias, ${ }^{31}$ un papel activo en la secularización de esta parcela del ordenamiento; primero, mediante sentencias interpretativas en las que extendió en términos equitativos la tutela penal a confesiones distintas a la católica y, finalmente, con la declaración de inconstitucionalidad del delito de "vilipendio de la religión de Estado". En la actualidad, y tras una reforma del Código Penal llevada a cabo en 2006, en el ordenamiento italiano puede decirse que se ha producido un tránsito completo de la tutela de la religión a la tutela de los sentimientos religiosos de los ciudadanos. En este sentido, con la reforma, el Código Penal va a tutelar a las confesiones religiosas frente a las ofensas que éstas puedan recibir, no a través de ataques directos a sus dogmas, sino a través del vilipendio de quienes las profesan, o de sus objetos y lugares sagrados. $^{32}$

\section{La tipificación de la blasfemia en clave moderna: Irlanda}

Es paradigmático dentro del panorama europeo el caso de la República de Irlanda, donde la Constitución compromete al Estado con la tipificación penal de la blasfemia, ${ }^{33}$ aunque, hasta fechas recientes, el legislador no había cumplido con dicho mandato constitucional, de tal forma que, en principio, la blasfemia sobrevivía como un delito de common law, ya que, como es sabido, éste rige como derecho supletorio en Irlanda siem-

30 Una lectura crítica de la primera línea jurisprudencial de la Corte a la luz de las exigencias de los principios constitucionales la podemos encontrar dos trabajos clásicos de Crisafulli, Vezio, "Art. 7o. della Costituzione e vilipendio della religione dello Stato", Arch. Pen., 1950, pp. 415-419, y Baldassarre, Antonio, "E'costituzionale la incrimiazione della bestfemia?" Giurisprudenza Costituzionale, 1973, pp. 69 y ss., en especial p. 78.

31 Di Salvatore, Enzo, "II sentimiento religioso nella giurisprudenza costituzionale", Giurisprudenza Costituzionale, 2002, pp. 4421 y ss.

32 Véase, ampliamente, Cianito, Cristiana, "Dalla tutela delle confessioni religiose alla tutela del sentimiento religioso individuale: l'incompleta transformazione dell'ordenamento italiano", Revista General de Derecho Canónico y Derecho Eclesiástico del Estado, núm. 30, 2012.

33 Concretamente, el artículo 40.6 de la Constitución irlandesa, en su párrafo primero, y tras afirmar la libertad de expression, establece que "The publication or utterance of blasphemous... matter is an offence which shall be punishable in accordance with law". 
Esta revista forma parte del acervo de la Biblioteca Jurídica Virtual del Instituto de Investigaciones Jurídicas de la UNAM

pre y cuando no contradiga la Constitución de la República. Ahora bien, se daba la paradoja de que, como hemos visto, dentro del common law el delito de blasfemia amparaba únicamente a la Iglesia de Inglaterra, de tal forma que en Irlanda este delito había servido precisamente para condenar por blasfemia católicos irlandeses beligerantes contra el anglicanismo. Por este motivo, y al amparo de un supuesto concreto, como fue Corway v. Independent Newspapers, ${ }^{34}$ el Tribunal Supremo entendió que no había fundamento normativo para condenar la blasfemia en Irlanda, ya que en este caso el common law presuponía la existencia de una Iglesia de Estado, algo que era incompatible con la Constitución irlandesa. ${ }^{35} \mathrm{El}$ Tribunal Supremo transmitió así al Parlamento irlandés la responsabilidad de paliar esta omisión legislativa aprobando una ley que tipifique la blasfemia en términos acordes con la Constitución. ${ }^{36}$ A pesar de que este pronunciamiento fue visto por algunos como la oportunidad para modificar la Constitución irlandesa eliminando la blasfemia de los límites a la libertad de expresión, finalmente, el camino tomado fue el contrario, y el Parlamento irlandés aprobó la que puede decirse que es la última ley que incrimina la blasfemia aprobada en Europa. Se trata, en cierto modo, de una ley que va contracorriente de lo que, como se ha dicho, constituye una tónica común en los países europeos, que es la progresiva afirmación de la libertad de expresión frente a cualquier intento de tutela del dogma religioso. En cualquier caso, lo cierto es que, al igual que decíamos con respecto al artículo 525 el Código Penal español, si tomamos en consideración los términos concretos de esta ley contra la blasfemia, parece muy difícil aventurar que se puedan producir persecuciones exitosas. El nuevo tipo penal no sólo exige la constatación de que las expresiones publicadas o dichas ofendan gravemente los contenidos considerados sagrados por cualquier confesión, sino que, a su vez, es necesario que estas expresiones se manifiesten de tal forma que ofendan a los integrantes de esas religiones, debiéndose probar, asimismo, que existía un ánimo específico de ofender. Igualmente, la ley incorpora una cláusula de exención de la responsabilidad cuando el demandado pueda probar la existencia de un

\footnotetext{
34 Irish Supreme Court, Corway v. Independent Newspapers, 30th July, 1999.

35 Corway v. Independent Newspapers, párrs. 13-26.

36 Jacob, Katherine A. E., "Defending Blasphemy: Exploring Religious Expression Under Ireland's Blasphemy Law”, 44 Case Western Reserve fournal of International Law, 803, en especial pp. 817-838.
} 
Esta revista forma parte del acervo de la Biblioteca Jurídica Virtual del Instituto de Investigaciones Jurídicas de la UNAM

"genuino valor literario, artístico, político, científico o académico" en la expresión que se ha considerado ofensiva. ${ }^{37}$

\section{La concepción premoderna de la blasfemia: Grecia}

Si, como hemos visto, los delitos de blasfemia o de difamación de la religión han revisado, por lo menos parcialmente, su fundamento, orientándose hacia la protección de otros valores jurídicos, perviven en Europa exponentes de una comprensión premoderna de la blasfemia; es decir, vinculada a la protección del fundamento moral del Estado. Este es el caso de Grecia, un país en donde, como pone de manifiesto la propia jurisprudencia de Tribunal Europeo de Derechos Humanos, la separación Iglesia-Estado no alcanza en ocasiones el estándar mínimo con base en el cual se entiende que la libertad religiosa del ciudadano es posible. Paradójicamente, como nos cuenta Michael Tsapogas, los antecedentes históricos de la protección penal de la blasfemia en Grecia eran liberales. Como ocurre en otros muchos países, el Código Penal griego de 1834 recibe la influencia directa del Código de Bávaro, y con ello de la obra de Feuerbach, quien sobre este particular asunto partía del presupuesto de que Dios no es susceptible de ofensa, de tal forma que la tutela penal de lo divino únicamente podía vincularse a la protección de la paz social. ${ }^{38}$ De esta forma, sin bien, en origen, la tutela penal frente a la blasfemia era extensiva a religiones diversas de la griega ortodoxa, la evolución del ordenamiento griego y de la propia jurisprudencia respondió a una clara lógica confesional. Así, pese a que la tutela contra la blasfemia y la difamación religiosa es extensiva a otras religiones, ${ }^{39}$ en la práctica todas las condenas penales han sido en supuestos donde era

37 Defamation act 2009, disponible en http://wrerw.irishstatutebook.ie/pdf/2009/en.act.2009. 0031.pdf.

38 Tsapogas, Michael, "Blasphemy and Justice in a Greek Orthodox Contest", en Venice Commission, Blasphemy Insult and Hatred: Finding Answers in a Democratic Society, p. 113.

39 En concreto, los términos en los que el Código Penal griego tipifica la blasfemia y la difamación religiosa son los siguientes (utilizamos la traducción al inglés del ya citado dossier de la Comisión Venecia: Blasfhemy Insult and Hatred..., cit., p. 178):

"Article 198-Malicious blasphemy

1. Anyone who insults God in public and with malicious intent, in any way whatsoever, shall incur a prison sentence of up to two years. 
Esta revista forma parte del acervo de la Biblioteca Jurídica Virtual del Instituto de Investigaciones Jurídicas de la UNAM

la Iglesia ortodoxa griega la agraviada. ${ }^{40}$ Se puede decir, en este sentido, que el delito de blasfemia sobrevive en Grecia vinculado a la protección de la religión del Estado, o si se prefiere, a la defensa de la estructura moral cristiana de la sociedad griega. Hay que decir que, lejos de ser potenciales, en Grecia, las restricciones a la libertad de expresión con base en estos tipos penales son ciertas. Sólo hace falta remontarse al año 2012 para encontrar la última condena penal por difamación de la religión, que en este caso recayó sobre el científico Philippos Loizos, quien a través de Facebook había hecho mofa de un monje candidato a canonización por la Iglesia griega. Puede decirse que Philippos Loizos es, hasta la fecha, el último condenado por blasfemia en Europa.

\section{La tutela de la religión como garantía de la paz social: Alemania}

La difamación religiosa también está tipificada como delito en Alemania. Como es conocido, la democracia alemana ostenta un grado específico de militancia con respecto al del resto de países europeos, de tal forma que, en distintos ámbitos, los valores constitucionales constituyen un límite al discurso y a los propios proyectos políticos. En el caso de la tutela frente a aquellos discursos que puedan atacar el contenido dogmático de las religiones, el Código Penal alemán va a situarse nuevamente en estos parámetros restrictivos, tipificando como delito la difamación de cualquier religión. No obstante, el artículo 166 del Código Penal, que tipifica la difamación de las Iglesias y de las creencias de los ciudadanos, no va a situar el bien jurídico protegido en los sentimientos religiosos, sino en la garantía de la paz social. Así, la publicación o difusión de materiales que injurien a la religión, a las creencias de terceros, a las Iglesias oficiales en el territorio de Alemania o cualquier otra asociación religiosa, está tipi-

2. Anyone who blasphemes in public in circumstances other than those specified in paragraph 1, thereby showing a lack of respect towards God, shall incur a prison sentence of up to three months.

Article 199-Insulting a religion

Anyone who insults the Eastern Orthodox Church or any other religion recognized in Greece, in public and with injurious intent, in any way whatsoever, shall incur a prison sentence of up to two years".

40 Véase, ampliamente, Sarafianos, Dimitris, "Blasphemy in the Greek Orthodox Legal Tradition”, Blasphemy Insult and Hatred..., cit., pp. 105-112. 
Esta revista forma parte del acervo de la Biblioteca Jurídica Virtual del Instituto de Investigaciones Jurídicas de la UNAM

ficada como delito únicamente en los supuestos en los que tal difamación se realice de forma que sea susceptible de afectar a la paz social.

Pese a que el tipo penal hace una mención específica a los cultos católico y protestante, en tanto cultos que están establecidos en Alemania, puede afirmarse que la lógica de la tipificación del delito de difamación religiosa responde no tanto a un residuo de confesionalidad como a otros motivos. Así, en primer lugar, el artículo 166 del Código Penal alemán mira al pasado y, en este sentido, forma parte de la respuesta jurídica frente a cualquier forma a través de la cual pueda articularse el discurso del antisemitismo. Pero, del mismo modo, la tipificación del delito de difamación religiosa denota, en clave contemporánea, una comprensión concreta de las "tareas del pluralismo", ${ }^{41}$ en virtud de la cual el Estado ha de implementar determinados instrumentos normativos para protegerse de discursos que puedan poner en riesgo la convivencia pacífica de sus ciudadanos.

\section{Dinamarca: las caricaturas de Mahoma y el nuevo blasfemo}

Esta última idea nos lleva a aproximarnos a la que a la postre ha constituido la experiencia más significativa en Europa, que es la danesa, la cual nos va a servir como punto de partida para una reflexión de carácter general. La blasfemia en Dinamarca está tipificada como delito en el Código Penal en unos términos que permanecen inalterados desde 1930, ${ }^{42}$ llamando la atención el hecho de que, pese a que en Dinamarca, como es sabido, no existe separación entre la Iglesia y el Estado, al ser un modelo luterano de Iglesia de Estado, el tipo penal hace extensiva la protección penal frente a la blasfemia a todas las denominaciones religiosas. De hecho, ante la ausencia de tipos penales específicos contra el odio racial, la tipificación de la blasfemia sirvió en la década de los treinta como instrumento normativo para la protección de las minorías, hasta el punto de que las únicas condenas por blasfemia se dirigieron contra

41 Häberle, Peter, La libertad fundamental en el Estado constitucional, Granada, 2003, pp. 40 y ss.

42 Demmark Criminal Code, paragraph 140: "Any person who, in public, mocks or scorns the religious doctrines or acts of worship of any lawfully existing religious community in this country shall be liable to imprisonment for any term not exceeding four months" (trad. al inglés de Comisión Venecia, Blasfhemy Insult and Hatred..., cit., p. 162). 
Esta revista forma parte del acervo de la Biblioteca Jurídica Virtual del Instituto de Investigaciones Jurídicas de la UNAM

miembros del Partido Nacional Socialista danés por sus declaraciones antisemitas. ${ }^{43}$ Es más, la pervivencia del delito de blasfemia frente a los sucesivos intentos de derogación se justificó precisamente en la necesidad de proteger a las nuevas minorías religiosas — principalmente la islámicaque se consolidaban en el país fruto de la inmigración..$^{44}$ En este sentido, la experiencia danesa parecía situarse dentro de las coordenadas propias de la era postsecular, mientras que en la mayoría de los países europeos el tipo penal de la blasfemia seguía vinculado a una suerte de defensa de la moralidad religiosa y a la idea de la religión de Estado. Sin embargo, contradictoriamente, en la década de los ochenta, y de la mano de la provocación artística, la discusión sobre la blasfemia va a volver a situarse en sus parámetros clásicos, que son los de la defensa del cristianismo, como religión de los daneses. La polémica que dio origen a esta discusión fue la subvención por parte del Estado de la producción de la obra cinematográfica de Jens Jorgen Thorsen, The Maney Faces of Jesus Christ, en la cual Jesucristo era retratado como un borracho con una licenciosa vida sexual. Más allá de que dentro del país la obra suscitara la movilización de ciertos sectores de la sociedad solicitando medidas legales contra su autor, la película provocó un verdadero conflicto diplomático en Dinamarca, siendo vetada en diversos países en los que se habían producido amenazas contra su exhibición. ${ }^{45}$

Más de veinte años más tarde, una sátira contra el islam realizada, en este caso, mediante una serie de caricaturas del profeta Mahoma publicadas por el semanario conservador Fyllands-Posten la cuestión de la blasfemia en Dinamarca, y podríamos decir también que en Europa, iba a situarse en el contexto de una sociedad postsecular. ${ }^{46}$ En este sentido, lo

43 Engelbreth Larsen, Signe, "Towards the Blasphemous Self: Constructing Societal Identity in Danish Debates on Blasphemy Provision in the Twentieth and Twenty-first Centuries", Fournal of Ethnic and Migration Studies, 2014, vol. 40, núm. 2, pp. 196 y 197.

44 Ibidem, pp. 198 y 199.

45 Finalmente, el autor no fue condenado al desistir el Ministerio Público en las acciones penales, pero le fueron retiradas todas las ayudas públicas a la producción por "la naturaleza inmoral del contenido". Véase, Engelbreth Larsen, Signe, "Towards the Blasphemous Self...”, cit., pp. 202 y 203. Igualmente, veáse el amplio epígrafe dedicado a Dinamarca en Blasfhemy Insult and Hatred: Finding Answers in a Democratic Society, cit., 246-260.

46 Como es conocido, en el islam existe una tradición iconofóbica, principalmente en la tradición sunita, que condena la representación del profeta Mahoma. La intención explícita del periódico fue desafiar los temores existentes frente a este tabú religioso y situar 
Esta revista forma parte del acervo de la Biblioteca Jurídica Virtual del Instituto de Investigaciones Jurídicas de la UNAM

primero que nos indica el suceso de las caricaturas de Mahoma es que, en la sociedad actual, el viejo blasfemo que ataca al corazón de la moralidad cristiana va a convivir con uno nuevo, quien, desde su educación libérrima y secular, provoca las exacerbadas formas de la religiosidad de sus conciudadanos. Como ha explicado muy bien Larsen, la diferencia sustancial entre uno y otro reside, en este sentido, en que el primero se situaba al margen del ethos social cristiano, era un outsider, mientras que el segundo basfema, desde dentro de la comunidad política, y con ello es, paradójicamente, un blasfemo insider. No obstante, este carácter de insider no obsta para que, en último término, también pueda ser molesto para la propia cultura secular que defiende, la cual es, a fin de cuentas, la que va a tener que afrontar las reacciones de las comunidades ofendidas por su ataque a la religión. ${ }^{47}$ Hay quien ha apuntado, con acierto, que era mucho más incómoda, y con ello más épica, la situación de quien, desde la marginalidad, se atrevía a cuestionar la doctrina moral mayoritaria u oficial que la de aquellos que hoy, desde la esencia de la comunidad política, dirigen sus críticas o parodias frente a las creencias de una minoría religiosa. ${ }^{48}$ No obstante, esta idea debe ser matizada en algún punto, y es que tampoco es preciso olvidar que la irreverencia del nuevo blasfemo puede también estar provista de un contenido épico. A este respecto, son de sobra conocidas, en este sentido, las vicisitudes que tuvo que soportar el escritor Salman Rushdi tras la publicación de Los versos satánicos, incluida la fatua del ayatola Homeini, poniendo precio a su muerte. ${ }^{49}$ Menos suerte corrió el polémico director holandés Theo van Gogh, a quien el estreno de su película Submission, en la cual exponía el sometimiento y las humillaciones que padecen las mujeres en la sociedad islámica le acabó costando la vida, siendo asesinado por un joven de origen marroquí en las calles de Amsterdam, después de haber recibido diversas amenzas por parte de

al islam en una igual posición frente a la libertad de expresión que el resto de religiones. De entre las doce caricaturas, una de ellas resultó especialmente polémica. En ella aparecía el profeta Mahoma con una suerte de turbante bomba, en el que se podía leer la consigna islámica "no hay más Dios que Alá y Mahoma es su Profeta".

47 Engelbreth Larsen, Signe, "Towards the Blasphemous Self...”, cit., pp. 205 y 206.

48 Todorov, Tzvetan, El miedo a los bárbaros, Madrid, 2014, pp. 188-192.

49 Sobre la particular odisea que tuvo que afrontar Rushdie desde la publicación de Los versos satánicos dan buena cuenta las recientes memorias del propio autor Anton, Joseph, Salman Rushdie. Memorias, 2013, en especial pp. 240-368. 
Esta revista forma parte del acervo de la Biblioteca Jurídica Virtual del Instituto de Investigaciones Jurídicas de la UNAM

la comunidad musulmana de su país. En este sentido, debe reconocerse que en el debate actual sobre la prohibición de la blasfemia o el insulto religioso, el miedo constituye un elemento sustancial. Así, junto a la idea de proteger los sentimientos religiosos de aquellas minorías que puedan sentirse agredidas por ciertos discursos para favorecer su integración, se encuetra aquella otra que podría resumirse de la siguente forma: protejamos los sentimientos religiosos de ciertas minorías porque eso es necesario para protegernos a nosotros.

En cualquier caso, el affaire de las caricaturas de Mahoma ha puesto de manifiesto las propias contradicciones con las que Europa afronta los desafíos de la pluralidad. Y es que el europeo no deja de ser un espacio donde los procesos de secularización son diacrónicos y donde es muy dispar el tratamiento jurídico de la religión en función de las distintas tradiciones nacionales. Sin embargo, la reacción frente a la publicación de las caricaturas de Mahoma, lejos de ser un problema nacional, siguió una dinámica viral y acabó por erigirse en una suerte de desafío cultural común, ${ }^{50}$ que puso sobre la mesa la cuestión de si es necesario repensar el alcance de la libertad de expresión en el contexto de pluralismo religioso que - con sus matices - es propio a todas las democracias occidentales.

\section{LA BLASFEMIA Y LA DIFAMAGIÓN DE LA RELIGIÓN EN EL DERECHO INTERNAGIONAL. LA EUROPA DE LA ONU Y LA EUROPA Del Tribunal Europeo de Derechos Humanos}

Frente al problema global que han representado determinados supuestos de blasfemia o difamación de la religión, como el de Los versos satánicos o el de las caricaturas de Mahoma, se han querido presentar también soluciones globales dirigidas a repensar los límites de la libertad de expresión en el

50 Como es sabido, tras las amenzas sufridas por el diario danés Fyllands-Posten, diversos diarios erupeos publicaron las caricaturas en señal de solidaridad, sufriendo estos medios en muchos casos las mismas amenazas que el seminario danés. Las protestas contra la publicación de estas caricaturas y contra la propia pasividad del gobierno danés a la hora de censurarlas, se extendieron de forma virulenta por diversos países musulmanes cobrándose más de un centenar de muertos. Para un relato detallado del desarrollo de estos sucesos, puede verse Ferreiro Galguera, Juan, "Las caricaturas de Mahoma y la jurisprudencia del Tribunal Europeo de Derechos Humanos", Revista Electrónica de Estudios furídicos, núm. 12, 2006, pp. 1-8. 
Esta revista forma parte del acervo de la Biblioteca Jurídica Virtual del Instituto de Investigaciones Jurídicas de la UNAM

ámbito de la crítica religiosa..$^{51}$ Así, desde 1999, Pakistan, con el apoyo de la Organización de Cooperación Islámica, ha iniciado una ofensiva diplomática en Naciones Unidas para promover una serie de resoluciones que insten a los Estados a sancionar en sus países la difamación de la religión. ${ }^{52}$ El objetivo declarado de esta ofensiva es el de combatir la "islamofobia" en aquellos lugares donde la minoría musulmana se puede ver expuesta a la estigmatización religiosa. Determinadas reacciones contra los atentados del 11 de septiembre y el propio suceso de las caricaturas de Mahoma en Dinamarca fueron determinantes para que esta iniciativa prosperara, aprobándose sucesivamente, entre 1999 y 2010, distintas resoluciones, tanto en el Comité y el Consejo de Derechos Humanos como en la propia Asamblea General de Naciones Unidas, en las cuales se instaba a tomar medidas jurídicas en el ámbito interno para prohibir la difamación de la religión. ${ }^{53}$ No obstante el éxito de algunas de estas iniciativas, lo cierto es que las mismas evidenciaron una clara fractura en torno a la cuestión dentro de la Organización, ya que ninguno de los países occidentales sufragaron la iniciativa, al considerarla una amenaza para el derecho a la libertad de expresión, y también, una suerte de apoyo implícito a las severas leyes antiblasfemia vigentes en diversos países musulmanes. ${ }^{54}$ En los Estados Unidos, las diversas resoluciones aprobadas fueron fuertemente criticadas por la diplomacia del país, y también en el propio ámbito académico. ${ }^{55}$ Del

51 Para un relato detallado de lo que el autor atinadamente califica como traducción en soft law de un desencuentro de mentalidades en torno a la libertad y la religión en el ámbito de las $\mathrm{Na}$ ciones Unidas, véase Palomino, Rafael, "Libertad de expresión y religión”, Ius Canonicum, XLIX, núm. 98, 2009, pp. 523 y ss.

52 U.N Econ. \& Soc. Council, Commission on Human Rights, Drft. Res.: Racism, Racial Discrimination, Xenophobia and all forms of Discriminations, U.N. Doc. E/CN.4/1999/L.40 (20 de abril de 1999).

53 Un relato del proceso de negociación de cada una de estas resoluciones lo podemos encontrar en el documento elaborado por The Becket Fund for Religious Liberty, "Defamation of Religions", disponible en http://wrew.becketfund.org/files/a9e5b.pdf .

54 En este sentido, véase, en extenso, Bitt, Robert C., "The Bottom up Journey of «Defamation of Religion» from Muslim States to the United Nations: A case Study of the migration of Anti-Constitutional Ideas", 56 Studies in Law, Politics and Society, Especial Issue Human Rights: New Possibilities/New Problems, 2011.

55 Pueden verse, entre otros muchos, Belnap, Alison G., "Defamation of Religions: A Vage and Overbroad Theory That Threatens Basic Human Rights", Brigham Young University Law Review, 2010, pp. 635 y ss.; Bill, Robert C., "Defamations of Religion: Rumors of its Death are Greatly Exaggerated", 62 Case Western Review Law Review, 2011, pp. 347 y ss.; Temperman, Jeroen, "Freedom of Expression and Religious Sensitivities in Pluralistic 
Esta revista forma parte del acervo de la Biblioteca Jurídica Virtual del Instituto de Investigaciones Jurídicas de la UNAM

mismo modo, la Asamblea Parlamentaria del Consejo de Europa aprobó en $2006^{56}$ y $2007^{57}$ sendas resoluciones, en las que se recomendaba a los Estados, eliminar cualquier tipo de respuesta penal contra la blasfemia o contra la difamación religiosa.

En cualquier caso, la posición de los Estados europeos en Naciones Unidas y las propias resoluciones del Consejo de Europa no dejan de ser contradictorias con la disparidad de opciones y la ambigüedad con la que, como hemos visto, se tutela la religión frente a determinados discursos en el ámbito europeo. A este respecto, el propio Tribunal de Derechos Humanos ha reconocido un importante margen de apreciación a los Estados a la hora de regular las ofensas religiosas. Como es sabido, las dos sentencias sobre las que se construye el esquema de análisis del Tribunal Europeo en los supuestos de conflicto entre la libertad de expresión y la tutela de los sentimientos religiosos, son las conocidas Otto-Preminger Institute contra Austria ${ }^{58}$ y Wingrove contra Reino Unido. ${ }^{59}$ En ambos casos el material conflictivo en cuestión era cinematográfico. En concreto, se trataba de dos obras satíricas, con explícitos episodios sexuales o casi pornográficos, que implicaban, en el primer caso, a Dios, Jesucristo y la Virgen, y en el segundo, a nuestra santa, Teresa de Ávila. La exhibición de ambas películas fue prohibida por las autoridades nacionales con el fundamento de proteger los sentimientos religiosos, sin que el Tribunal de Derechos Humanos considerara en ningún supuesto que dichas prohibiciones supusieran una injerencia en la libertad de expresión contraria al Convenio. En mi opinión, la jurisprudencia de Otto Preminger y Wingrove constituye un precedente que ha envejecido mal. Como es sabido, en todas aquellas cuestiones relacionadas con la gestión pública del pluralismo religioso, el Tribunal de Estrasburgo ha mantenido una especial deferencia hacia las autoridades nacionales al amparo de la doctrina del margen

Societies: Facing the Challenge of Extreme Speech", Brigham Young University Law Review, 201 1, pp. 729 y ss.; Langer, Lorenz, "The Rise (and Fall?) of Defamation of Religions", 35 Yale Fournal of International Law, Winter, 2010, pp. 257 y ss.

56 Parliamentary Assembly of the Council of Europe: Resolution 1510 (2006), Freedom of Expression and Respect for Religious Beliefs.

57 Parliamentary Assembly of the Council of Europe: Recommendation 1805 (2007), Blasphemy, Religious Insults and Hate Speech Against Persons on Grounds of Their Religion.

58 STEDH, Otto Preminger Institute c. Austria, 24 de septiembre 1994.

59 STEDH, Wingrove c. Reino Unido, 25 de noviembre de 1996. 
Esta revista forma parte del acervo de la Biblioteca Jurídica Virtual del Instituto de Investigaciones Jurídicas de la UNAM

de apreciación nacional..$^{60}$ En este caso también, al amparo de esta teoría del margen de apreciación y con base en el hecho de que no puede hallarse una moral común o un concepto transnacional de lo religioso en el ámbito del Convenio, el Tribunal avanzó la idea de que la protección de los sentimientos religiosos puede constituir un fundamento legítimo para que los Estados, en determinados supuestos, consideren imponer determinadas restricciones de la libertad de expresión, en tanto medidas necesarias en una sociedad democrática. Como pusieron de manifiesto hasta tres jueces en su opinión particular al fallo del Tribunal en Otto Preminguer, este último no deja de ser un argumento problemático, y es que es más que discutible la idea de que los sentimientos religiosos puedan considerarse un valor amparado por el Convenio, y más aún, situar el interés en proteger estos sentimientos a la misma altura que la propia libertad de expresión. Y es que, aunque en el corazón del Convenio se encuentre la protección de la libertad religiosa, lo cierto es que en este tipo de supuestos no nos encontramos ante ningún tipo de agravio a esta libertad, sino ante la tutela jurídica frente a aquellas reacciones emocionales que puedan provocar en ciertas personas y en la propia sociedad, determinadas aproximaciones irreverentes al fenómeno religioso. ${ }^{61}$

De todas las formas, aun aceptando que legítimamente un Estado puede considerar que por su historia y por la propia configuración religiosa de su sociedad ciertos discursos irreverentes con la religión pueden crear problemas reales de convivencia, y, con base en ello, establecer ciertos límites, lo cierto es que tales medidas restrictivas deberían ser siempre juzgadas a la luz de su proporcionalidad, lo que implica, como ha señalado la juez Tulkens, evitar en este tipo de conflictos el sacrificio absoluto de uno de los valores jurídicos en liza. Esto es, en buena medida, lo que no hace en ninguno de estos dos casos el Tribunal Europeo de Derechos Humanos, que legitima una restricción absoluta de la libertad de expresión cuando el marco reducido en el que estaba prevista su exhibición podía

60 Entre otras muchas, STEDH, Kokkinakis c. Grecia, 25 de mayo de 2003; STEDH, Leyla Sahin c. Turquía (Gran Sala) 10 de noviembre de 2005; STEDH, Cha'are Shalom Ve Tsedek c. Francia, 27 de junio de 2000.

61 "The Convention does not, in terms, guarantee a right to protection of religious feelings. More particularly, such a right cannot be derived from the right to freedom of religion, which in effect includes a right to express views critical of the religious opinions of others". STEDH, Otto Preminger Institute c. Austria (Joint dissenting opinion of Judges Palm, Pekkanen and Makerczyk), párr. 6. 
Esta revista forma parte del acervo de la Biblioteca Jurídica Virtual del Instituto de Investigaciones Jurídicas de la UNAM

haberle servido para conciliar los bienes jurídicos en juego sin necesidad de sacrificar esta libertad. ${ }^{62}$

$\mathrm{Al}$ margen de esto, creo que una de las carencias más importantes de ambas sentencias reside en el hecho de que el Tribunal no logra esbozar un concepto autónomo de la libertad artística como subespecie de la libertad de expresión. Así, después de recordar el carácter basilar de la libertad de expresión dentro del marco axiológico del Convenio, el Tribunal alude a la necesidad de deslindar aquellas opiniones o expresiones molestas que estarían amparadas por la libertad de expresión, de aquellas otras gratuitamente o innecesariamente ofensivas. El problema, en mi opinión, es que el criterio de si son necesarias o no ciertas expresiones ofensivas para transmitir un juicio de valor, si bien puede servirnos para excluir ciertos mensajes del ámbito amparado por la libertad de expresión, no es igualmente válido, o por lo menos no puede trasladarse con total analogía, al ámbito concreto de la libertad artística donde, al margen de las ideas que quiera transmitir, el artista, por lo general y principalmente, también va a querer provocar emociones. En este sentido, y aunque ya insistiremos en esto más adelante, tomarse en serio la libertad artística exige que el creador tenga un importante margen de irreverencia en la composición de la obra y en la elección de los propios instrumentos a través de los cuales quiere provocar determinadas emociones.

A la vista de lo señalado, puede decirse que en el Tribunal Europeo de Derechos Humanos la libertad artística recibe el tratamiento de una libertad de perfil bajo una suerte de subespecie de la libertad de expresión, cuya contribución democrática o institucional se entiende que es menor $\mathrm{y}$, por lo tanto, susceptible de ser sacrificada en caso de conflicto con otros bienes jurídicos. En gran medida, este diagnóstico queda confirmado con la jurisprudencia posterior de Estrasburgo en supuestos en los que también

62 Tulkens, Françoise, "Conflicts Between Fundamental Rights: Contrasting Views on Articles 9 and 10 of the European Convention of Human Rights", Blasphemy Insult and Hatred: Finding Answers in a Democratic Society, cit., pp. 121-133. En cualquier caso, también es cierto que no hay que perder de vista que tanto en Otto Preminger como en Wingrove no nos encontrábamos ante supuestos de tutela penal de las religiones, sino que en ambos casos las medidas restrictivas de la libertad de expresión estaban dirigidas únicamente a la impedir la exhibición de ambos trabajos. A la luz de la jurisprudencia del Tribunal sobre delitos de expresión no parece aventurado predecir que el juicio no hubiera sido el mismo si además de las medidas dirigidas a evitar la exhibición de ambos trabajos, los Estados hubieran impuesto una sanción penal a sus autores. 
Esta revista forma parte del acervo de la Biblioteca Jurídica Virtual del Instituto de Investigaciones Jurídicas de la UNAM

se produce un conflicto entre la libertad de expresión y la tutela de ciertas religiones y sentimientos religiosos, pero en los cuales no es la libertad artística sino la libertad de opinión la que da origen al litigio. Este sería el caso de Ginewski c. Francia ${ }^{63}$ en el cual el Tribunal consideró que contradecía el artículo 10 del Convenio la sanción civil impuesta a un periodista que en un artículo de prensa había vinculado la doctrina de la Iglesia católica con el antisemitismo y con el propio genocidio del pueblo judío. Y también el de Aydin Tatlav c. Turquía, ${ }^{64}$ un supuesto en el cual la mayoría de los jueces concluyen que Turquía había vulnerado el Convenio al condenar penalmente al autor de un libro que juzgaba con severidad la religión islámica, ${ }^{65}$ En ambos casos, y al contrario de lo que vimos en Otto Preminger y en Wingrove, la naturaleza institucional de la libertad de expresión en una sociedad democrática conduce al Tribunal a afirmar su posición preferente frente a las tentativas de excluir del debate público ciertas opiniones que pueden considerarse ofensivas para determinados grupos religiosos.

Que la libertad artística no posea este, si se me permite, carisma liberal, en el seno de la jurisprudencia del Tribunal Europeo puede no ser una cuestión menor en este caso. Y es que, en el tema que nos ocupa, ha sido precisamente a través de la libertad artística como se ha puesto de manifiesto con más nitidez la relación de tensión que existe entre la protección de la religión y el paradigma liberal que es inherente a las democracias pluralistas. Los versos satánicos de Rushdie o las caricaturas del profeta Mahoma no sólo son manifestaciones de la libertad creativa, sino también, o, mejor dicho, sobre todo, de la esencia crítica de la cultura liberal. Es por ello que, si bien en muchas ocasiones ante un "caso difícil", lo lógico es replegarse en las características particulares del conflicto y no intentar abstraernos del mismo para llevar a cabo reflexiones de carácter general; en supuestos como los mencionadas, por el contrario, a raíz de concretas manifestaciones artísticas, nos vemos obligados a enfrentarnos a una reflexión general sobre la compatibilidad de ciertas limitaciones de la libertad de expresión con los presupuestos liberales de nuestros sistemas políticos.

63 STEDH, Ginewski c. Francia, 13 de enero 2010.

64 STEDH, Aydin Tatlav c. Turquía, 2 de mayo 2006.

65 Sobre esta jurisprudencia, véase, ampliamente, Martínez Torrón, Javier, "La ofensa a la religión como límite a la libertad de expresión: la experiencia europea", Medios de Comunicación y Pluralismo Religioso, Consell de l'Audiovisual de Catalunya, marzo de 2010, pp. 79-100. 
Esta revista forma parte del acervo de la Biblioteca Jurídica Virtual del Instituto de Investigaciones Jurídicas de la UNAM

\section{LA TIPIFICAGIÓN DE LA BLASFEMIA Y LOS PRESUPUESTOS DE LA GULTURA LIBERAL}

Para esta reflexión general a la que se acaba de aludir, creo que como punto de partida es necesario descartar un postulado a menudo erróneamente sobreentendido, que es el de que tras la tipificación penal de la blasfemia se encuentra el interés jurídico de proteger la libertad religiosa. El derecho a la libertad religiosa nos ampara para determinar libremente nuestra respuesta ante el interrogante religioso y a actuar conforme a nuestras creencias, $y$, en este sentido, la tutela penal de la libertad religiosa constituye una tutela frente a la coacción, ya sea para declarar o no declarar nuestras creencias, o bien para participar o no en determinados actos de carácter religioso. Sin embargo, en ningún caso es deducible de la libertad religiosa un derecho a la indemnidad de nuestras creencias frente a la crítica de los demás. La prohibición penal de la blasfemia o la difamación religiosa, lejos de tutelar la libertad religiosa, lo que hace es tutelar el poder de la religión, bien entendido como factor de cohesión nacional, o bien en clave contemporánea, como elemento reactivo, susceptible de provocar grietas en la paz social. ${ }^{66}$ Por resumir, y decirlo de una forma clara, la libertad religiosa que está en el corazón de un orden liberal nos ampara a creer que Jesucristo es hijo de Dios, pero desde un punto de vista conceptual no puede extenderse a la pretensión de que se prohíba que esta aseveración se discuta o se tome en broma por parte de alguien.

En segundo lugar, cualquier reflexión sobre la protección penal del dogma o del honor de las religiones ha de hacerse sobre la base de esa circunstancia de la justica propia de las democracias occidentales, que es el pluralismo razonable de doctrinas comprensivas del bien, y, en este contexto, lo cierto es que tomar en serio dicha protección constituye una tentativa imposible. En la línea de lo apuntado por el juez Frankfurter en foseph Burstyn, Inc. v. Wilson, en una sociedad donde coexisten una pluralidad de doctrinas religiosas no hay forma de que la exteriorización de las creencias de uno no suponga un contradicción, a veces frontal, con las creencias de otro. Así, el ateísmo militante de unos puede ofender a ciertos fervorosos creyentes, del mismo modo que la espera del Mesías que aguardan otros puede ser ofensiva para los que tienen por dogma que éste ya se hizo hom-

66 Aunque en este segundo caso, en realidad, estamos más ante un control del poder de la religión, que ante una tutela de su poder. 
Esta revista forma parte del acervo de la Biblioteca Jurídica Virtual del Instituto de Investigaciones Jurídicas de la UNAM

bre, o el trinitarismo de unos puede resultar una idea insoportablemente sacrílega para otros unitarios.

Por otro lado, como muy bien ha puesto de manifiesto el suceso de las caricaturas de Mahoma, en el ser humano la esfera de las creencias religiosas constituye un ámbito hipersensible a la crítica. Ahora bien, si aceptamos que la especial sensibilidad de ciertas personas con respecto a los dogmas de su fe es óbice para impermeabilizar jurídicamente estas doctrinas frente a cualquier juicio de valor crítico, estaríamos vaciando de contenido el derecho a la libertad de expresión en este ámbito y, con ello, parte del propio valor emancipador de este derecho. Y es que de los dogmas de fe se derivan también pautas morales que inciden en la vida social, y que como tales no pueden permanecer al margen de la de la crítica. La premisa de que todo dogma es falible en el ámbito de la esfera pública no deja de ser, en este sentido, una de las características que se asumen como esenciales a una sociedad abierta.

No se puede olvidar, asimismo, que la sensibilidad religiosa posee también una geometría variable. Así, aquellas comunidades religiosas con un equipaje dogmático más amplio y menos habituado a la crítica liberal van ser más susceptibles de sentirse ofendidas. Sin embargo, la propia lógica del principio de igualdad impide que esta asimetría en la sensibilidad religiosa sirva de justificación para que en la esfera pública determinadas formas de religiosidad se conviertan en límites específicos, de la libertad de expresión del resto. Del mismo modo, desde el punto de vista propiamente procesal, el delito de blasfemia plantea otro problema específico, y es el de que el Estado difícilmente podrá sustituir a las confesiones a la hora de valorar qué resulta ofensivo para su corpus doctrinal. Es decir, el Estado puede emitir un juicio sobre cuándo se ha producido un alegato virulento u ofensivo contra una comunidad o grupo religioso que afecte a su dignidad social o a sus estatus moral, pero difícilmente podrá enjuiciar sin el concurso de la propia comunidad religiosa cuándo dicha ofensa se ha producido, no contra la comunidad en sí misma o contra sus miembros, sino contra la esencia de su corpus doctrinal. ${ }^{67}$

67 La sustitución del Estado en este juicio implicaría una confusión de funciones civiles y religiosas incompatible con lo que podríamos decir que constituye el estándar mínimo de secularización de un Estado constitucional. Sobre este último concepto y a propósito de la sentencia del Tribunal Europeo de Estrasburgo sobre el Partido de la Prosperidad turco, véase Garain, Alain, "La laïcité, príncipe érigé en valeur de la 
Esta revista forma parte del acervo de la Biblioteca Jurídica Virtual del Instituto de Investigaciones Jurídicas de la UNAM

No son difíciles de imaginar tampoco supuestos en los que la tutela penal de las doctrinas religiosas pueda plantear un desafío a otro de los elementos esenciales de la cultura liberal como es la libertad científica. Concretamente, en relación con los monoteísmos fundados sobre ciertos relatos históricos, es sabido que el estudio de la vida de los santos o profetas puede dar lugar a tesis absolutamente ofensivas para quienes forman parte de determinadas confesiones, al contradecir éstas los relatos que son bendecidos como ciertos por la tradición religiosa. El racionalismo europeo se enfrentó a este desafío durante el siglo XVIII, y es de sobra conocida, a este respecto, la incidencia que tendría La vida de Jesús de Ernest Renan, como obra pionera en la aproximación histórica a la figura de Jesús de Nazaret. ${ }^{68}$ Una obra que humanizó el mito del Dios Hombre a través de un relato materialista apartado de los dogmas evangélicos. Esta aproximación a la vida de Jesús le supuso a su autor el apelativo de "blasfemo europeo", impuesto por el papa Pío IX, pero, en cualquier caso, inició el camino para que el sometimiento de los relatos religiosos a la contradicción histórica o científica sea considerado un presupuesto de nuestra cultura, sin que sea susceptible de ningún límite fundado en una suerte de patente religiosa sobre ciertas narraciones.

Como ya se ha dicho, de la misma forma que los artistas han sido quienes mejor han sabido sublimar el sentimiento religioso, también han sido ellos quienes con más intensidad han explorado el terreno de la desfachatez religiosa. El discurso artístico, la libertad de creación, en definitiva, no sólo ha puesto en cuestión lo decente, sino también ha hecho lo propio con lo sagrado. En este sentido, es inherente a esta libertad artística una suerte de "derecho a la irreverencia", por usar la expresión que, precisamente a raíz del debate sobre las caricaturas de Mahoma, empleara el escritor Mario Vargas Llosa. ${ }^{69}$ Sólo en el siglo XX son múltiples, en este sentido, los ejemplos de que el artista se hace a sí mismo desde un pathos

Convention Européene des droits de l'homme", Le Dalloz, París, núm. 2, 12 de enero de 2006, pp. 106-108.

68 La vie de Jesús de Ernst Renan fue publicada en París en 1963, y a los pocos meses de publicación ya habían sido vendidos más de 60,000 ejemplares, siendo traducida posteriormente a diversas lenguas europeas. Sobre el impacto de la obra de Renan tuvo en su contexto histórico y en relación con otros trabajos biográficos sobre Jesús de la misma época, puede verse Mark, Allan Powell, Jesus as a figure in History, Westminster, John Knox Press, en especial, 1998, pp. 15-17.

69 Vargas Llosa, Mario, "El derecho a la irreverencia", El País, 22 de febrero de 2006. 
Esta revista forma parte del acervo de la Biblioteca Jurídica Virtual del Instituto de Investigaciones Jurídicas de la UNAM

marginal enfrentado a la moralidad de su época. ${ }^{70}$ Del mismo modo, como explicó George Bataille en su ensayo sobre el erotismo, es evidente que en muchas ocasiones la emoción artística se ha construido precisamente a través de la profanación, de la violación de lo sagrado. ${ }^{71} \mathrm{El}$ artista es, en definitiva, el violador natural del tabú, y sin este juego con lo prohibido no se entiende buena parte de la historia del arte.

Como hemos podido ver a propósito de la jurisprudencia del TEDH en los asuntos Wingrove y Otto Preminguer, la libertad artística carece de una construcción conceptual acabada desde un punto de vista jurídico, y puede decirse que disfruta de una protección de perfil bajo. La razón de ello reside, en gran medida, en el hecho de que a la libertad artística se le niega la dimensión institucional que le es reconocida a la libertad de expresión cuando lo que se transmiten son ideas, juicios de valor o hechos veraces. Se presupone, en definitiva, que la contribución a la cultura democrática que hace el arte no es tal como para que la libertad artística tenga un peso específico en un juicio de ponderación cuando pueda entrar en conflicto con otros bienes jurídicos. Una presunción que, en mi opinión, no hace sino desconocer la fuerza emancipadora que la obra de arte y los propios movimientos artísticos han desempeñado a lo largo de la historia. ${ }^{72}$ Con relación a esto último, creo que deben ser tomadas con cierta prudencia las invitaciones que se hacen para distinguir entre el legítimo arte emancipador y aquel otro innecesariamente ofensivo. Es cierto, como ha explicado muy bien Tushnet, que en este terrero el jurista siempre pisa una zona de sombra, en la que no resulta fácil en ocasiones reconocer ante una determinada obra si nos encontramos o no ante un ejercicio de la libertad artística y, sobre todo, adivinar cuál es el discurso que subyace tras ella. ${ }^{73}$ Sin embargo, ante la tentativa de deslindar lo emancipador de lo ofensivo, no está de más echar la vista a la historia para comprobar cómo lo que en un momento es considerado sancionable pronto se transforma en emancipador. ${ }^{74}$

70 Puede verse, en este sentido, el clásico de Water, Benjamin, "Charles Baudelaire. Un lírico en la época del altocapitalismo”, Obras, libro I, vol. 2, en especial pp. 91-168.

71 Bataille, George, El erotismo, Barcelona, 2010, en especial pp. 67-75.

72 Eberle, Edward J., "Art as Speech", 11 University of Pennsylvania Fournal of Law and Social Change, 2007-2008, pp. 1-19.

73 Tushnet, Mark, "Art and the First Amendment", 35 Columbia Fournal of Law \& the Arts, pp. 169-220.

74 Sobre esta idea, puede verse, en extenso, Hamilton, Marci A., "Art Speech", 49 Vanderbilt Law Review, 1996, pp. 79-121. 
Esta revista forma parte del acervo de la Biblioteca Jurídica Virtual del Instituto de Investigaciones Jurídicas de la UNAM

Como se ha señalado en la doctrina americana, la primera enmienda; es decir, la libertad de expresión, muchas veces encuentra sus héroes imprevistos y emancipadores, precisamente entre aquellos que en un determinado momento encarnan los discursos más problemáticos y molestos. ${ }^{75}$

Hasta aquí se ha hecho una crítica a la tipificación penal de la blasfemia o de la difamación religiosa, desde presupuestos abiertamente liberales. Por ello, en último término, creo que es necesario tomar en consideración la propia crítica al tratamiento liberal de las ofensas a la religión. El eje fundamental de esta crítica parte de que los ataques contra las creencias religiosas de las personas no son fundamentalmente distintos que aquellos que van dirigidos contra la raza o el sexo. Es decir, al contrario de lo que se asume en la cultura liberal, las creencias religiosas no son para todos los ciudadanos una elección personal ni tampoco pueden considerarse como algo separado de las propias personas, sino que, en determinadas comunidades, la religión estaría adscrita a sus miembros de una forma casi biológica, de tal forma que habría de entenderse que cualquier ataque a los dogmas de su religión infunde también un grave daño moral a la comunidad y a sus propios fieles. ${ }^{76}$ En este sentido, la defensa de la libertad de expresión que hacemos los liberales frente a cualquier límite basado en la protección de una determinado cuerpo de creencias religioso se haría desde una cierta incapacidad cultural para comprender que las representaciones de Mahoma o los libros como Los versos satánicos de Ruhsdie vulneran "la estructura natural del afecto" de ciertos ciudadanos y que por ello han de estar perseguidos penalmente. En la raíz de

75 Schauer, Frederick, "The Heroes of the First Amendment", 101 Michigan Law Review, May, 2003, quien, entre otros ejemplos, llama la atención sobre los procesos jurídicos por obscenidad que tuvieron que librar obras clásicas de la literatura del siglo XX, como el Ulysses de Joyce, Trópico de Cáncer y Trópico de Capricornio de Henry Miller, El amante de Lady Chatterley de D. H. Lawrence o Una Tragedia Americana de Theodore Dreiser. Sobre fuerza emancipadora del arte es obligada también la referencia al proceso penal por sodomía que padeció Oscar Wilde, y cómo, a través de su furibunda defensa de la libertad artística, se articulaba una defensa general de la libertad personal: "the form of government that is most suitable to the artist is no government at all". En este sentido, pueden verse las páginas que dedica a este episodio de la vida del escritor Richard Ellman, en su monumental biografía, Óscar Wilde, Londres, 1987, en especial pp. 434-449.

76 Sobre esta cuestión, y en contestación a la crítica comunitaria, seguimos el trabajo del profesor de Yale, March, Andrew F., "Speech and the Sacred: Does the Defense of Free Speech Rest on a Mistake about Religion? (2010)", Political Theory, vol. 40, junio de 2012, pp. 318-345.

D. R. C 2016. UNAM, Instituto de Investigaciones Jurídicas, Boletín Mexicano de Derecho Comparado, núm. 146, pp. 305-341. 
Esta revista forma parte del acervo de la Biblioteca Jurídica Virtual del Instituto de Investigaciones Jurídicas de la UNAM

esta incapacidad se encontraría una concepción de la religión como algo electivo y privado que no puede ser asumida generalmente por todas las comunidades religiosas. ${ }^{77}$

Esta crítica a la postura liberal frente a la blasfemia o la difamación religiosa que se realiza desde el comunitarismo más radical es una crítica que fácilmente se puede comprender, pero que al mismo tiempo es difícil de aceptar desde los presupuestos básicos sobre los que se sostienen nuestros sistemas políticos. Según esta idea casi biológica de las creencias, la identidad religiosa se transforma en algo no sólo no criticable, sino tampoco negociable, de tal forma que, sin necesidad de llevar el argumento al extremo, podríamos concluir que el proselitismo de cualquier tipo o la propia defensa del ateísmo tendrían que estar perseguidos por el derecho. En definitiva, la tipificación penal de la blasfemia es difícil de conciliar con la cultura liberal. En este sentido, la negativa a perseguir a quienes atacan ciertas ideas religiosas con su discurso nos hace ser conscientes de que la neutralidad liberal excluye ciertas pretensiones y puede defraudar a algunas comprensiones de vida. ${ }^{78}$

\section{LA BLASFEMIA Y EL DISGURSO DEL ODIO RELIGIOSO. UNA DISTINCIÓN NEGESARIA}

Como conclusión final a este trabajo, quisiera hacer hincapié en la necesidad de distinguir desde el punto de vista jurídico la cuestión de la blasfemia o la difamación de la religión, de los problemas que plantea el discurso del odio y, en concreto, el discurso del odio religioso. Una idea sobre la que han insistido los informes tanto del Consejo de Europa como de la propia Comisión Venecia, y sobre la que vale la pena detenerse. ${ }^{79}$

En primer lugar, no está de más hacer alusión al hecho de que, por lo menos en la tradición patria, la blasfemia ha sido culturalmente algo que podríamos calificar de íntimo, de tal forma que lo común no ha sido increpar al Dios ajeno, sino al de uno mismo; de manera que dificilmente puede verse en este tipo de expresiones la intencionalidad propia del denominado discurso del odio; es decir, la de menoscabar el estatuto moral

\footnotetext{
77 Ibidem, p. 324.

78 Berlin, Isaiah, El fuste torcido de la Humanidad, Barcelona, 2002.

79 Venice Commission, Blasphemy, Insult and Hatred: Finding Answers in a Democratic Society, núm. 47, pp. 32, conclusión 89.
} 
Esta revista forma parte del acervo de la Biblioteca Jurídica Virtual del Instituto de Investigaciones Jurídicas de la UNAM

de una persona o de una comunidad. A este respecto, ya decía el maestro Juan de Mairena que "la blasfemia forma parte de la religión popular", a lo que añadía, "desconfiad de un pueblo donde no se blasfema; lo popular allí es el ateísmo. Prohibir la blasfemia con leyes punitivas, más o menos severas, es envenenar el corazón del pueblo obligándole a ser insincero en su diálogo con la divinidad". ${ }^{80}$

Más allá de esta aclaración respecto a la "blasfemia a la española", creo que a la hora de deslindar la difamación religiosa o la blasfemia de lo que propiamente es el discurso del odio religioso puede resultar interesante acercarse a la obra de uno de los pocos autores liberales norteamericanos que han defendido la necesidad de limitar el discurso del odio: el profesor Jermery Waldron. ${ }^{81}$ La tesis de Waldron se puede resumir de la siguiente forma: en primer lugar, para el profesor de Columbia, hay que aceptar que el discurso puede efectivamente dañar. Al contrario de lo que desde Mill hasta Dworkin es aceptado por la ortodoxia liberal, Waldron asume que a través de la libertad de expresión no sólo se puede ofender, sino que se puede producir un daño real en las personas. ${ }^{82}$

El segundo postulado liberal que es cuestionado por Waldron es el de que la verdad necesariamente va a prevalecer en el mercado de las ideas. En su opinión, no son pocos los ejemplos históricos que ponen de manifiesto cómo la infamia se hace hegemónica en la sociedad. En este sentido, para Waldron, el liberalismo pecaría de una cierta ingenuidad al asumir que el discurso es siempre el remedio contra el discurso. Desde estos presupuestos el autor defiende la necesidad de ofrecer desde el derecho una tutela frente a determinados discursos, que pueden afectar a la dignidad de las personas, entendida ésta como el estatuto moral sin el cual la persona carece de autonomía como miembro de una sociedad..$^{83}$

Ahora bien, cuando aborda la cuestión de qué tratamiento jurídico ha de darse a aquellos discursos que son susceptibles de herir las sensibilidades de determinados creyentes, Waldron insiste en la necesidad de distinguir los ataques concretos contra un cuerpo de creencias o símbolos, de aquellos otros dirigidos contra el estatuto moral de ciertas personas o comunidades por razón de su religión. Y es que sólo en el segundo

80 Machado, Antonio, Fuan de Mairena, Madrid, 2009, t. I, p. 77.

81 Waldron, Jeremy, Harm in Hate Speech, Harvard, 2012.

82 Ibidem, pp. 105-116.

83 Ibidem, pp. 15-18.

D. R. C 2016. UNAM, Instituto de Investigaciones Jurídicas, Boletín Mexicano de Derecho Comparado, núm. 146, pp. 305-341. 
Esta revista forma parte del acervo de la Biblioteca Jurídica Virtual del Instituto de Investigaciones Jurídicas de la UNAM

caso nos encontraríamos realmente ante un supuesto de discurso del odio, frente al cual ha de reaccionar el derecho. Pese a que en los supuestos de blasfemia o de difamación de la religión podemos constatar la existencia una ofensa, para Waldron no es posible comprobar la presencia de un daño propiamente dicho. La respuesta jurídica, y más en concreto, la respuesta penal frente a determinados discursos, ha de plantearse en este sentido, no tomando en consideración las meras ofensas que puedan sufrir los sentimientos religiosos de los ciudadanos, sino el daño efectivo que estos discursos puedan provocar en su estatuto moral. En lo que Waldron insiste, en definitiva, y con lo que nosotros estamos de acuerdo, es en la necesidad de distinguir la crítica hacia las creencias o las ideas, cualquiera que sea su modalidad e intensidad, del ataque contra las personas y las comunidades por razón de sus creencias. ${ }^{84}$ El derecho puede reprimir legítimamente aquellos ataques que vayan dirigidos a eliminar el estatuto moral de ciertos ciudadanos en la sociedad por el hecho de profesar una determinada confesión, pero si entendemos que cualquier ataque a nuestras creencias es un ataque a nuestra dignidad, que debe ser perseguido, estaríamos situando el respeto a las personas en un ámbito incompatible con los presupuestos liberales.

Es cierto que, como a menudo ocurre en el mundo del derecho, esta distinción no siempre es fácil. Una cosa es denunciar a través de una sátira aquellos aspectos de la doctrina islámica que pueden fundamentar la idea de guerra santa, y otra pintar dianas con el Corán en el medio en un barrio musulmán. Los supuestos de incitación al odio religioso, en muchas ocasiones, van a ser conflictivos, y será necesario contextualizar el discurso concreto para determinar si nos encontramos ante una crítica al cuerpo dogmático de una religión que toda sociedad liberal ha de admitir, o ante un discurso que incita al odio o la violencia amenazando a ciertas personas por razón de su religión. Por ejemplo, si uno lee la sentencia del Tribunal Correccional de Paris ${ }^{85}$ en el caso Charlie Hebdo se convence de

\section{Ibidem, pp. 118-131.}

85 La publicación satírica francesa Charlie Hebdo fue una de las revistas europeas que se solidarizaron con Fyllands-Posten publicando las famosas viñetas. En este caso, además de publicar un número especial con la reproducción de las caricaturas, situó en su portada un retrato del profeta Mahoma con el subtítulo C'est dur d'être aimé par des cons. La Unión de Organizaciones islámicas de Francia y la Gran Mezquita de París interpusieron acciones penales contra esta publicación por un delito de injurias públicas contra un grupo de personas por razón de su religión. Finalmente, el Tribunal Correccional de París absolvió al 
que con aquella portada en la que Mahoma se quejaba de los integristas, la intención de la publicación no era denigrar a los musulmanes, sino criticar el fundamentalismo de ciertas interpretaciones coránicas. ${ }^{86}$

En todo caso, las parodias o críticas frente a determinados dogmas religiosos confirman que las confesiones religiosas no son guetos impermeables ni autistas, sino que son también parte de la comunidad política, y que por ello pueden ser el objeto de la libertad de crítica que es propia del sistema en el que conviven. En este sentido, la blasfemia o la irreverencia

medio, al considerar que se trataba de un ejercicio de la libertad de expresión, en el que a través de la sátira se quería hacer crítica del fundamentalismo y no injuriar a la comunidad musulmana. TGI Paris, 17e ch. corr., 22 mars 2007: Juris-Data núm 2007-327959, disponible en http://wwwedroitdesreligions.net/pdf_tgi/20072203.pdf. TGI Paris, 17e ch. corr., 22 mars 2007: Juris-Data núm. 2007-327959, disponible en http://wrww.droitdesreligions.net/ pdf_tgi/20072203.pdf.

86 Cosa distinta es que la manera en la que se transmita esa crítica nos pueda parecer moralmente censurable por provocadora. Como insiste Tzventan Todorov en una publicación reciente, en contextos donde la islamofobia no sólo tiene referentes sociales, sino en los que también diversos grupos políticos han flirteado con este discurso, conviene mirar con desconfianza la presencia en la opinión pública de determinados discursos construidos sobre el estigma cultural. Del mismo modo, es lógico pensar que allí donde la integración es compleja, contribuye poco al diálogo democrático el transmitir ciertos mensajes a través de fórmulas que podemos considerar conscientemente provocadoras, como pueden ser las caricaturas del profeta Mahoma. No obstante, conviene no olvidar que si bien tomarse en serio la libertad de expresión conlleva la protección de estas formas de expresión irreverentes e incómodas, esto no significa que las mismas no se puedan condenar, de tal forma que las propias minorías ofendidas puedan encontrar la solidaridad de muchos de sus compatriotas. Del mismo modo, nada impide que las comunidades religiosas puedan construir un discurso razonado acerca de por qué este tipo de manifestaciones son impertinentes, consiguiendo que tales argumentos calen en la opinión pública, generándose así un clima de rechazo hacia este tipo de manifestaciones, de tal forma que, sin necesidad de prohibirlas, las mismas se vean socialmente censuradas. Este acuerdo informal en la opinión pública sobre la impertinencia de determinadas expresiones ofensivas contra las creencias de algunos ciudadanos puede servir también para que se generen pautas de autocensura dentro de los medios de comunicación, de tal forma que se evite la proliferación de aquellas expresiones que son especialmente molestas para algunos ciudadanos. Se trataría, en este caso, de una autocensura, entendida no como la aceptación tácita de un chantaje, la capitulación ante un temor, o la consecuencia de un tabú, sino como un reconocimiento del otro y de sus razones. Tzvetan, Todorov, El miedo a los bárbaros, Madrid, 2014, pp. 199-215. Sobre la necesaria distinción de la censura en el plano jurídico-normativo, de las limitaciones lingüísticas impuestas derivadas otros conceptos como el tabú, lo políticamente correcto o la autocensura, es especialmente ilustrativo el trabajo de Alvárez Ortega, Miguel, "Repercusiones jurídico-políticas de la interdicción lingüística: tabú, censura y corrección política", Estudios de Deusto, vol. 58, 2010. 
religiosa no son algo nuevo que surja contra las minorías religiosas, sino que forman parte de la larga tradición de la libertad de expresión. Así, con la crítica, e incluso la burla que se pueda hacer de ciertas creencias de las nuevas minorías religiosas, no se está sino dando el mismo trato que se dio a las confesiones históricamente mayoritarias y que hubieron de comprender las estrecheces de la idea de infalibilidad en un régimen liberal. En este modelo liberal, las religiones, todas ellas, pueden hacer valer sus argumentos para censurar moralmente ciertas conductas y provocar su disfavor en la opinión pública. Lo que en ningún caso pueden pretender es que el que el Estado tipifique como delito o simplemente prohíba determinadas expresiones por el simple hecho de que puedan ser contrarias $\mathrm{u}$ ofensivas de aquellas creencias que ellas tienen como sagradas. 